\title{
Efficacy of Combination Treatment with Fingolimod (FTY720) Plus Pathogenic Autoantigen in a Glucose-6-phosphate Isomerase Peptide (GPI ${ }_{325-339}$ )-Induced Arthritis Mouse Model
}

\author{
Yuya Yoshida, ${ }^{a}$ Takumi Tsuji, ${ }^{a}$ Sayaka Watanabe, ${ }^{a}$ Ayane Matsushima, ${ }^{a}$ Yuki Matsushima, ${ }^{a}$ \\ Rie Banno, ${ }^{b}$ Tetsuro Fujita, ${ }^{c}$ and Takeyuki Kohno, ${ }^{*, a c}$ \\ ${ }^{a}$ Department of Pathological Biochemistry, Faculty of Pharmaceutical Sciences, Setsunan University; 45-1 \\ Nagaotoge-cho, Hirakata, Osaka 573-0101, Japan: ${ }^{b}$ Aizenbashi Hospital; 5-16-15 Nihonbashi, Naniwa-ku, Osaka \\ 556-0005, Japan: and ${ }^{c}$ Research Institute for Production and Development; 15 Shimogamo Morimoto-cho, Sakyo-ku, \\ Kyoto 606-0805, Japan. \\ Received April 16, 2013; accepted August 18, 2013; advance publication released online August 30, 2013
}

\begin{abstract}
Fingolimod (FTY720) is known to have a significant therapeutic effect in various autoimmune disease models. Here, we examined FTY720 in a model of rheumatoid arthritis, induced by immunizing DBA/1 mice with a peptide consisting of residues 325 through 339 of glucose-6-phosphate isomerase $\left(\right.$ GPI $\left._{325-339}\right)$. The efficacy was evaluated in terms of macroscopic findings, inflammatory cell infiltration and autoantibody level. Prophylactic administration of FTY720 from the day of immunization significantly suppressed the development of paw swelling, but therapeutic administration of FTY720 from onset of symptoms on day 8-9 was less

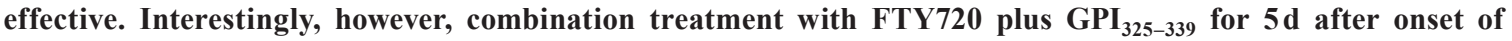
symptoms significantly reduced the severity of symptoms in all mice, and no relapse occurred after booster immunization. Taking into account the reported mechanism of action of FTY720, these results indicate that combination treatment with FTY720 plus pathogenic autoantigen might efficiently induce immune tolerance by sequestering circulating autoantigen-specific lymphocytes from blood and peripheral tissues to the secondary lymphoid tissues. Combination treatment with FTY720 plus pathogenic autoantigen may become a breakthrough treatment for remission-induction in patients with autoimmune diseases including rheumatoid arthritis.
\end{abstract}

Key words FTY720; rheumatoid arthritis; pathogenic autoantigen

Rheumatoid arthritis (RA) is a refractory autoimmune disease, characterized by synovial hyperplasia, mononuclear cell infiltration, cartilage degradation, joint destruction, pannus formation, and so on.,2) Biological agents such as antitumor necrosis factor (TNF)- $\alpha$ monoclonal antibody (mAb) and anti-interleukin (IL)- 6 receptor $\mathrm{mAb}$, that target specific molecules, provide an effective means for therapeutic management of RA due to their specificity and powerful functional capabilities. ${ }^{3)}$ However, such agents suffer from various disadvantages, such as induction of neutralizing antibodies and the occurrence of relapse after discontinuation of the drug. Thus, a therapy able to induce complete remission would be highly desirable.

Fingolimod (FTY720) is a synthetic structural analogue of myriocin (ISP-I), a metabolite of Isaria cinclarii. ${ }^{4,5)}$ The structure of ISP-I was subsequently modified in order to reduce its toxicity, to improve its physicochemical properties and to identify the essential structure for immunosuppressive activity, and a candidate compound, FTY720, was obtained. ${ }^{6}$ FTY720 was discovered by Tetsuro Fujita, of our group, in collaboration with Taito Co. and Yoshitomi Pharmaceutical Industries, Ltd. in Japan. Its efficacy has been well established in preclinical transplantation models (rat heart, liver, skin, and small intestine, dog kidney and monkey kidney). ${ }^{7)}$ Also, FTY720 has been reported to be effective in preventing the development of immunological diseases in various animal models, including models of multiple sclerosis, ${ }^{8)}$ myasthenia gravis, ${ }^{9}{ }^{9}$ atopic dermatitis ${ }^{10,11)}$ and type 1 diabetes mellitus. ${ }^{12,13)}$ The mechanism of action of FTY720 differs from that of

The authors declare no conflict of interest established immunosuppressants, such as tacrolimus hydrate and cyclosporine. FTY720 is converted in vivo by sphingosine kinase to FTY720 monophosphate (FTY720-P), which is the active form of the drug. FTY720-P acts as a high-affinity agonist for sphingosine 1-phosphate (S1P) receptors. FTY720 blocks S1P signaling by inducing receptor internalization and intracellular partial degradation. ${ }^{14-16)}$ As a result, FTY720 suppresses immune response by sequestering circulating mature lymphocytes from blood and peripheral tissues to the secondary lymphoid tissues and thymus. Even though the mechanisms of pharmacological action of FTY720 remain to be fully clarified, it is clear that FTY720 has no inhibitory effect on cytokine production, in contrast to established immunosuppressants. ${ }^{17,18)}$

In this study, we used glucose-6-phosphate isomerase (GPI) peptide-induced arthritis as an animal model of RA, because the model seems to be akin to human RA. GPI-induced arthritis is induced by immunization of DBA/1 mice with recombinant human GPI. ${ }^{19)}$ GPI-induced arthritis is different from collagen-induced arthritis (CIA), a commonly used animal model of human RA, with regard to the priority of T cells and B cells. ${ }^{2021)}$ In GPI-induced arthritis, administration of CD4 monoclonal antibody after onset rapidly ameliorates the arthritis, despite the absence of changes in anti-GPI antibody titer. Fragment crystallizable $\gamma$ receptor $(\mathrm{Fc} \gamma \mathrm{R}) \gamma$-chain-deficient mice are resistant to GPI-induced arthritis, and adoptive transfer of purified immunoglobulin $\mathrm{G}(\mathrm{IgG})$ antibodies alone is not able to induce arthritis in these mice. ${ }^{20,21)}$ The therapeutic efficacy of biological agents (anti-TNF- $\alpha$ mAb, anti-IL-6 $\mathrm{mAb}$ and cytotoxic T-lymphocyte antigen 4-immunoglobulin (CTLA 4-Ig)) on GPI-induced arthritis are similar to those in 
human RA. ${ }^{21)}$

As for CIA, autoantibodies are important players. Adoptive transfer of polyclonal IgG antibodies purified from the sera of arthritic mice with CIA can induce arthritis even in mouse strains that are not susceptible to actively induced CIA, ${ }^{22)}$ while, most attempts to induce CIA in mice by T-cell transfer have been unsuccessful and CD4-deficient mice develop CIA with unaltered incidence and severity. ${ }^{23-25)}$ Anti-IL-1 and anti-IL-12 mAbs significantly suppressed arthritis in CIA, ${ }^{26-29)}$ however, anti-TNF- $\alpha$ mAb had little effect, ${ }^{26)}$ and anti-CD20 and anti-IL6 receptor $\mathrm{mAbs}$ had no effect on established CIA. ${ }^{21,30,31)}$ Anti-CD4 mAb was ineffective in CIA mice after the mice had produced anti-CII antibody. ${ }^{20,32,33)}$ These findings indicated that the pathophysiological mechanisms of CIA might be different from those of human RA. Thus, it is considered that GPI-induced arthritis is a more suitable model for examining the effect of treatment. ${ }^{21)}$ Moreover, Iwanami et al. reported that the major epitope of $\mathrm{CD}^{+} \mathrm{T}$ cells in GPIinduced arthritis was human $\mathrm{GPI}_{325-339}$, and immunization with this peptide induced severe polyarthritis (designated here as $\mathrm{GPI}_{325-339}$-induced arthritis). ${ }^{34)}$

It has already been demonstrated that intravenously (i.v.) administration of pathogenic autoantigen ameliorates symptoms by inducing tolerance in another animal model of RA. ${ }^{35)}$ Also, administration of antigen induces rapid accumulation of antigen-specific cells in the parracortical regions of all lymph nodes, and most of the cells then rapidly disappeared, leaving behind a population that was hyporesponsive to antigenic stimulation. ${ }^{36}$ ) Thus, antigen-specific memory and tolerance can be influenced by antigen administration. ${ }^{36)}$ We considered that immune tolerance might be efficiently induced in the GPI $_{325-339}$ model if FTY720 induced efficient sequestration of autoantigen-specific lymphocytes in secondary lymphoid tissues. Based on the above considerations, we hypothesized that combination treatment with FTY720 plus pathogenic autoantigen might be an effective approach for inducing complete remission of RA. In the present study, we tested this idea in the $\mathrm{GPI}_{325-339}$-induced mouse model of RA.

\section{MATERIALS AND METHODS}

Animals and Ethics DBA/1 mice bred under specific pathogen-free conditions were purchased from SLC Inc., Shizuoka, Japan. The mice were given $\gamma$-ray-irradiated food (CRF-1, Oriental Bio Co., Kyoto, Japan) and distilled water for injection (Otsuka Pharmaceutical Co., Ltd., Tokyo, Japan). This study was performed according to Guidelines for Proper Conduct of Animal Experiments (Science Council of Japan, June 1, 2006) and the protocol was approved by the institutional animal care committee of Setsunan University. Throughout the experimental procedures, every effort was made to minimize the number of animals used and their suffering.

Agents 2-Amino-2-[2-(4-octylphenyl)ethyl]propane-1,3diol hydrochloride (FTY720) was kindly provided by Yoshitomi Pharmaceutical Industries, Ltd. (Japan). Peptide 325(IWYINCFGCETHAML)339 of glucose-6-phosphate isomerase $\left(\mathrm{GPI}_{325-339}\right)$ was purchased from Operon Biotech. K.K. (AL, U.S.A.).

Preparation of GPI $_{325-339}$-Induced Arthritis Mouse Model DBA/1 mice (7-week-old males) were immunized by intracutaneous injection of $\operatorname{GPI}_{325-339}(10 \mu \mathrm{g})$ with Freund's complete adjuvant containing Mycobacterium tuberculosis H37Ra (Difco) at the base of the tail. Pertussis toxin (200 ng; PT, Calbiochem, CA, U.S.A.) was injected i.v. on days 0 and 2. ${ }^{34)}$ The clinical symptoms of $\mathrm{GPI}_{325-339}$-induced arthritis in each limb were checked daily and graded on a clinical arthritis score of $0-4$, defined as follows: 0 , no evidence of erythema and swelling; 1, erythema and mild swelling confined to the tarsals or ankle joint; 2, erythema and mild swelling extending from the ankle to the tarsals; 3, erythema and moderate swelling extending from the ankle to metatarsal joint; 4, erythema and severe swelling encompass the ankle, foot and digits, or ankylosis of the limb. ${ }^{1)}$ The clinical scores of the four limbs were totaled for each mouse, yielding a maximum score of 16 .

Administration Schedules of Test Drugs To examine the prophylactic effect of FTY720 and GPI $_{325-339}$, mice with $\mathrm{GPI}_{325-339}$-induced arthritis were divided into four groups. The FTY720 group was given FTY720 in water $(1.0 \mathrm{mg} / \mathrm{kg}$, orally, six times a week; this dosing regimen is similar to that reported by Tsunemi et al. ${ }^{37)}$ ) from the day of immunization with $\mathrm{GPI}_{325-339}$ to day 22. The $\mathrm{GPI}_{325-339}$ group was given $\mathrm{GPI}_{325-339}$ alone in phosphate buffered saline (PBS) $(10 \mu \mathrm{g} / \mathrm{mouse}$, i.v. once daily) from the day of immunization to day 5 . The placebo group was given the vehicle alone on the same schedule as the FTY720 group. The non-immunized group was injected with Freund's complete adjuvant alone.

To examine the therapeutic effect of FTY720 and GPI ${ }_{325-339}$ on $\mathrm{GPI}_{325-339}$-induced arthritis, the same procedure as above was employed, except for timing of administration. FTY720 was administrated from the day of onset of symptom (day 8-9) to day 22. In $\mathrm{GPI}_{325-339}$ group, the treatment period was $5 \mathrm{~d}$, from the day of onset of symptom.

To examine whether combination treatment with FTY720 plus GPI $_{325-339}$ would induce immune tolerance, mice with $\mathrm{GPI}_{325-339}$-induced arthritis were divided into four groups. The FTY720 group was given FTY720 alone $(1.0 \mathrm{mg} / \mathrm{kg}$, orally, once daily). The $\mathrm{GPI}_{325-339}$ group was given $\mathrm{GPI}_{325-339}$ alone in PBS $(10 \mu \mathrm{g} /$ mouse, i.v. once daily). The combination group received both FTY720 and $\mathrm{GPI}_{325-339}$ at the above dosages, and the placebo group received vehicle alone. In these groups, the treatment period was $5 \mathrm{~d}$, from the time of onset of symptoms (day 9 after immunization) until day 13 .

Histochemical Staining On day 22 after immunization, the front limb joints were removed, fixed in $10 \%$ buffered formalin solution (Wako Pure Chemical Industries, Ltd., Osaka, Japan) for $2 \mathrm{~d}$, and decalcified with K-CX (Falma Co., Ltd., Tokyo, Japan) for $7 \mathrm{~d}$. Tissues were processed, embedded in paraffin and cut into $5 \mu \mathrm{m}$ sections. The sections were stained with hematoxylin-eosin (H\&E) using Mayer's Hematoxylin Soln. (Wako Pure Chemical Industries, Ltd.) or with goat anti-mouse CD3 mAb (Santa Cruz Biotechnology, Inc., CA, U.S.A.). Synovial hyperplasia and lymphocyte infiltration of carpal-metacarpal joints were histologically graded as follows: 1, normal; 2, mild; 3, moderate; 4, severe (histological score). ${ }^{38)}$ The histological score was evaluated blindly by three investigators and mean values were calculated.

Measurement of Anti-GPI 325-339 Total IgG Antibody Level Serum samples were collected for measurement of

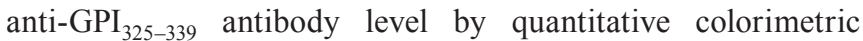
ELISA. Polystyrene microtiter wells (EIA flat plate-1, Sanko 
(A)

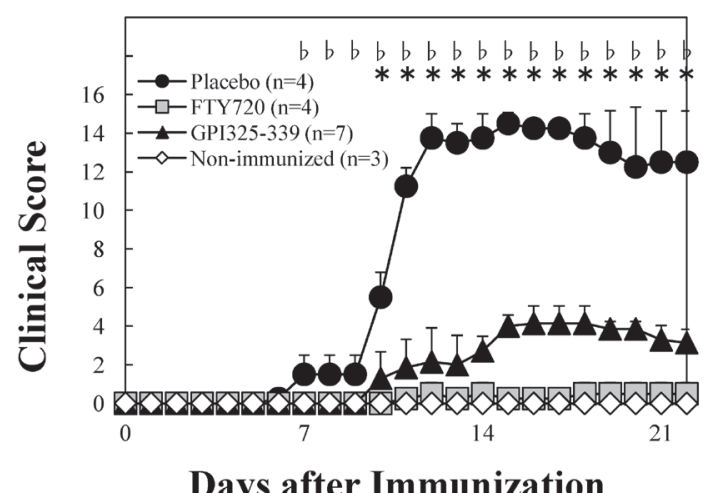

(B)

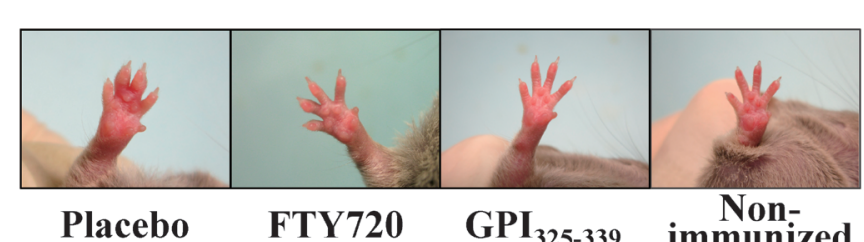

Fig. 1. Prophylactic Effect of FTY720 and $\mathrm{GPI}_{325-339}$ on $\mathrm{GPI}_{325-339}$-Induced Arthritis

Mice with $\mathrm{GPI}_{325-339}$-induced arthritis were treated with FTY720 or $\mathrm{GPI}_{325-339}$ from the day of immunization. (A) Clinical symptoms of arthritis were evaluated from the day of immunization to day 22, : the placebo group $(n=4), \square$ : the FTY720 group ( $n=4$, FTY720 $1.0 \mathrm{mg} / \mathrm{kg}$, orally, 6 times a week, from the day of immunization to day $22)$, $\mathbf{\Delta}$ : the $\mathrm{GPI}_{325-339}$ group ( $n=7, \mathrm{GPI}_{325-339} 10 \mu \mathrm{g} /$ mouse, i.v. once daily, from the day of immunization to day 5$)$ and $\diamond:$ the non-immunized group ( $\left.n=3\right)$. The significance of differences in clinical scores was examined (* (the FTY720 group $v s$. the placebo group), $b$ (the GPI $_{325-339}$ group $v s$. the placebo group) denotes $p<0.05$ ). (B) Photographs showing typical paws of non-immunized mice and GPI $_{325-339}$-induced arthritis mice with or without FTY720 or GPI $325-339$ treatment, taken on day 22 after immunization.

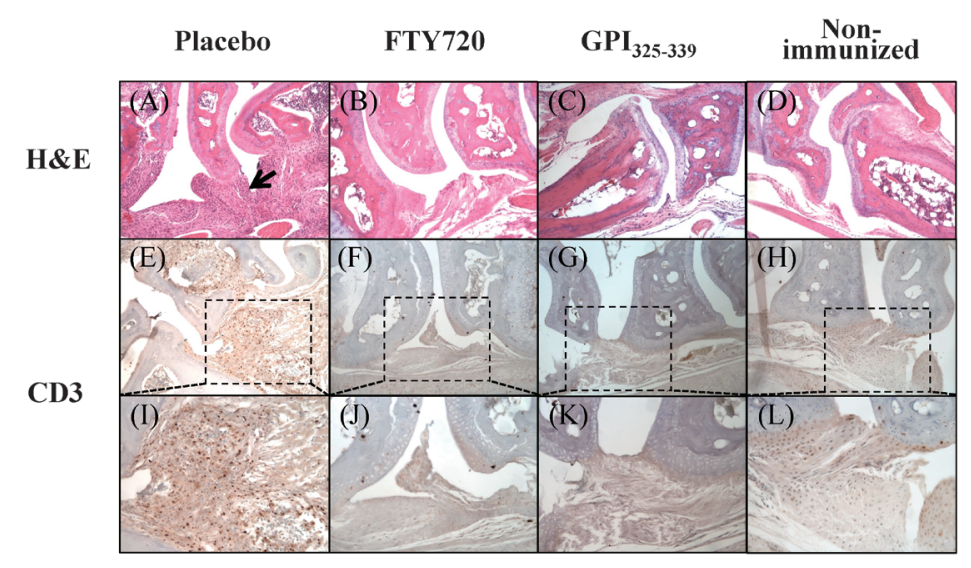

(M)

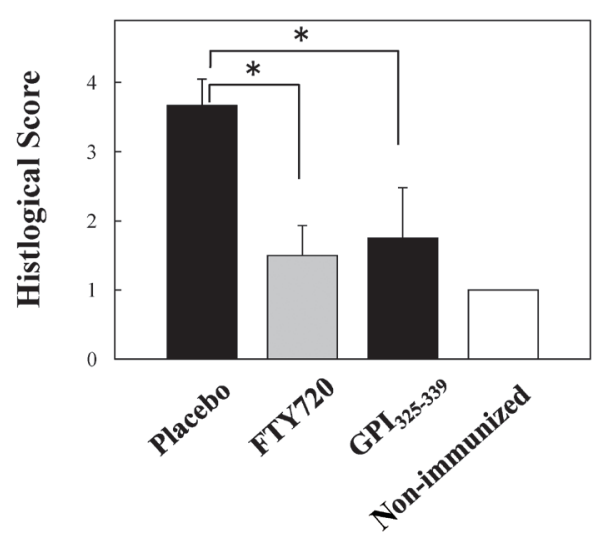

Fig. 2. Histological Staining of Carpal-Metacarpal Joints

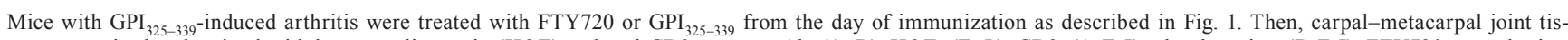
sues were excised and stained with hematoxylin-eosin (H\&E) and anti-CD3 mouse mAb. (A-D): H\&E. (E-L): CD3. (A,E, I): placebo mice. (B, F, J): FTY720 treated mice. $(\mathrm{C}, \mathrm{G}, \mathrm{K})$ : $\mathrm{GPI}_{325-339}$ treated mice. $(\mathrm{D}, \mathrm{H}, \mathrm{L})$ : non-immunized mice. A representative image from one mouse in each group is shown. The arrow indicates synovial hyperplasia and inflammatory cell infiltration. (M) Histological score is indicated as the mean+S.D. for all mice in each group $(*$ denotes $p<0.05)$. 
Junyaku Co., Tokyo, Japan) were coated with GPI $_{325-339}$ $(1.0 \mu \mathrm{g} / \mathrm{mL})$ in $0.1 \mathrm{M}$ sodium phosphate buffer, $\mathrm{pH} 7.5$, containing $0.1 \% \mathrm{NaN}_{3}$, at $4{ }^{\circ} \mathrm{C}$ overnight. After incubation, antigen solution was removed by aspiration, and the wells were washed 4 times with $0.25 \mathrm{~mL}$ of $10 \mathrm{~mm}$ sodium phosphate buffer, $\mathrm{pH} 7.0$, containing $0.1 \mathrm{M} \mathrm{NaCl}$. The washed wells were incubated with $0.25 \mathrm{~mL}$ of $10 \mathrm{~mm}$ sodium phosphate buffer, $\mathrm{pH}$ 7.0, containing $0.1 \mathrm{M} \mathrm{NaCl}, 0.1 \%$ bovine serum albumin (BSA, Nacalai Tesque Co., Ltd., Kyoto, Japan) and $0.1 \% \mathrm{NaN}_{3}$ at $4{ }^{\circ} \mathrm{C}$ for $3 \mathrm{~h}$. After incubation, the buffer was removed by aspiration, and the wells were incubated with serum samples that had been previously diluted (5000-fold) with the same buffer $(0.15 \mathrm{~mL})$, at $37^{\circ} \mathrm{C}$ for $3 \mathrm{~h}$ and $4^{\circ} \mathrm{C}$ overnight. After incubation, the diluted serum was removed by aspiration, and the wells were washed as above. The washed wells were incubated with goat (anti-mouse $\mathrm{IgG} \mathrm{H}+\mathrm{L}$ ) Fab'-horseradish peroxidase conjugate (Medical and Biological Laboratories Co., Ltd., Nagoya, Japan), which had been previously diluted 7500 -fold, with $10 \mathrm{~mm}$ sodium phosphate buffer, $\mathrm{pH} 7.0$, containing $0.1 \mathrm{M}$ $\mathrm{NaCl}$ and $0.1 \%$ BSA $(0.15 \mathrm{~mL})$, at $37^{\circ} \mathrm{C}$ for $3 \mathrm{~h}$. Finally, the conjugate solution was removed by aspiration, the wells were washed as above, and peroxidase activity bound to the wells was measured by colorimetry with $o$-phenylenediamine as a hydrogen donor. The absorbance at $490 \mathrm{~nm}$ was measured with a plate reader (Model 450, Bio-Rad Laboratories, Hercules, CA, U.S.A.).

Measurement of Anti-GPI ${ }_{325-339}$ IgG Subclass Antibody Level Anti-GPI ${ }_{325-339}$ IgG subclass $\left(\operatorname{IgG}_{1}, \operatorname{IgG}_{2 \mathrm{a}}, \mathrm{IgG}_{2 \mathrm{~b}}, \mathrm{IgG}_{3}\right)$ levels were detected with Mouse Monoclonal Antibody Isotyping Reagents (Sigma-Aldrich Co., LLC, MO, U.S.A.) according to the manufacturer's instructions.

Statistical Analysis The statistical significance of differences was evaluated by using the Mann-Whitney $U$-test. $p<0.05$ was considered significant.

\section{RESULTS}

Prophylactic Effect of FTY720 on GPI $_{325-339}$-Induced Arthritis In order to examine the prophylactic effect of FTY720, mice with GPI $_{325-339}$-induced arthritis were treated from the day of immunization to day 22. The clinical arthritis scores during this period are shown in Fig. 1A. In the placebo group, $\mathrm{GPI}_{325-339}$-induced arthritis-associated symptoms were observed at day 7, and became severe within the following week (Figs. 1A, B). In contrast, the administration of FTY720 from the day of immunization significantly suppressed the onset of $\mathrm{GPI}_{325-339}$-induced arthritis to a level similar to that of the non-immunized mice injected with adjuvant alone (Figs. 1A,B). To examine synovial hyperplasia and inflammatory cell infiltration, paraffin-embedded front carpal-metacarpal joints were stained with H\&E or anti-mouse CD3 mAb. Synovial hyperplasia and infiltration of $\mathrm{CD}^{+}$cell (T cell)-based inflammatory cells were observed in the placebo group, but were significantly suppressed in the FTY720 group (Fig. 2).

Therapeutic Effect of FTY720 on GPI $_{325-339}$-Induced Arthritis In order to examine the therapeutic effect of FTY720, mice with GPI $_{325-339}$-induced arthritis were treated from the day of onset of symptoms (day 8-9) to day 22. FTY720 reduced the severity of $\mathrm{GPI}_{325-339}$-induced arthritisassociated symptoms (Fig. 3A). The maximum score in the FTY720 group (10.9 \pm 5.3 , S.D.) was significantly lower than
(A)

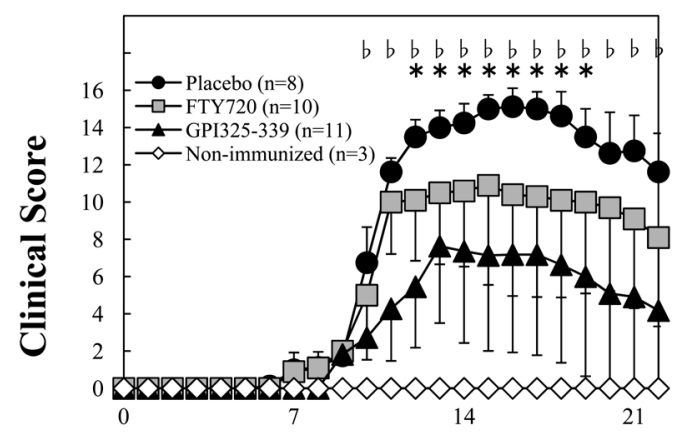

Days after Immunization

(B)

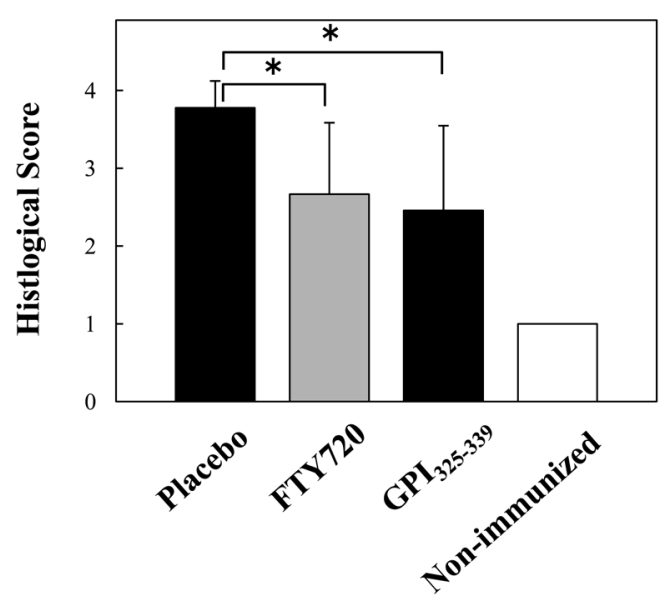

Fig. 3. Therapeutic Effect of FTY720 and $\mathrm{GPI}_{325-339}$ on $\mathrm{GPI}_{325-339^{-}}$ Induced Arthritis

Mice with GPI 325-339-induced arthritis were treated with FTY720 or GPI $_{325-339}$ from the day of onset of symptom (day 8-9). (A) Clinical symptoms of arthritis were evaluated from the day of immunization to day 22, $\mathbf{0}$ : the placebo group $(n=8), \square$ : the FTY720 group $(n=10$, FTY $7201.0 \mathrm{mg} / \mathrm{kg}$, orally, 6 times a week, from the day of onset of symptom to day 22), $\mathbf{\Delta}$ : the $\mathrm{GPI}_{325-339}$ group ( $n=11$, $\mathrm{GPI}_{325-339} 10 \mu \mathrm{g} / \mathrm{mouse}$, i.v. once daily, from the day of onset of symptom to day 5) and $\diamond$ : the non-immunized group $(n=3)$. The significance of differences in clinical scores was examined (* (the FTY720 group $v$ s. the placebo group), b (the GPI $_{325-339}$ group $v s$. the placebo group) denotes $p<0.05$ ). (B) Histological score is indicated as the mean+S.D. of all mice in each group (* denotes $p<0.05$ ).

that of the placebo group (15.1 \pm 1.0, S.D.). In addition, synovial hyperplasia and lymphocyte infiltration were significantly suppressed as compared with the placebo group (Fig. 3B).

Next, to examine the effects of FTY720 on $\mathrm{GPI}_{325-339^{-}}$-specific antibody production, serum samples were collected from mice in all groups on days $-1,8,15$ and 22 after immunization, and the anti-GPI 325-339 antibody level was measured by quantitative colorimetric enzyme-linked immunosorbent assay (ELISA). In the FTY720 group, the production of antiGPI $_{325-339}$ total IgG, IgG2a, IgG2b and IgG3 was significantly reduced as compared with the placebo group (FTY720 group vs placebo group on day 22: total $\mathrm{IgG}, 1.28 \pm 0.72$ vs. $2.65 \pm$ 0.93 ; IgG2a, $0.69 \pm 0.29$ vs. $1.35 \pm 0.27$; IgG2b, $1.35 \pm 0.58$ vs. $2.05 \pm 0.65$; IgG3, $0.23 \pm 0.18$ vs. $0.49 \pm 0.22$ ), while, no difference was observed in IgG1 level between FTY720 group $(1.41 \pm 0.69)$ and placebo group $(1.40 \pm 0.60)$ (Fig. 4). These results suggested that FTY720 might suppress the severity of symptoms by blocking synthesis of the complement-fixing IgG subclasses IgG2a, IgG2b and IgG3. However, FTY720 showed only a partial effect and was less effective than previously reported agents (anti-TNF- $\alpha \mathrm{mAb}$, anti-IL- $6 \mathrm{mAb}$ and CTLA $4-\mathrm{Ig})^{21)}$ 
(A) Total IgG

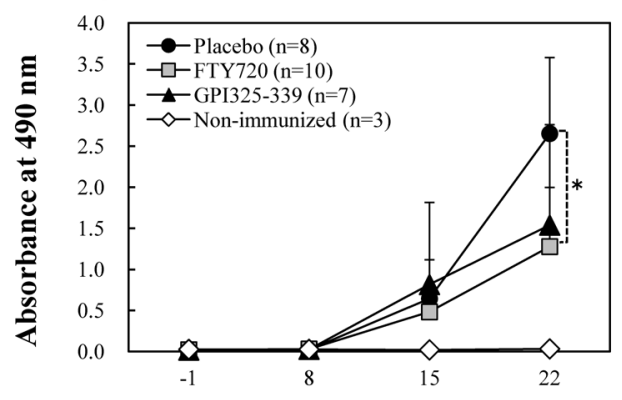

Days after Immunization

(C) IgG2a

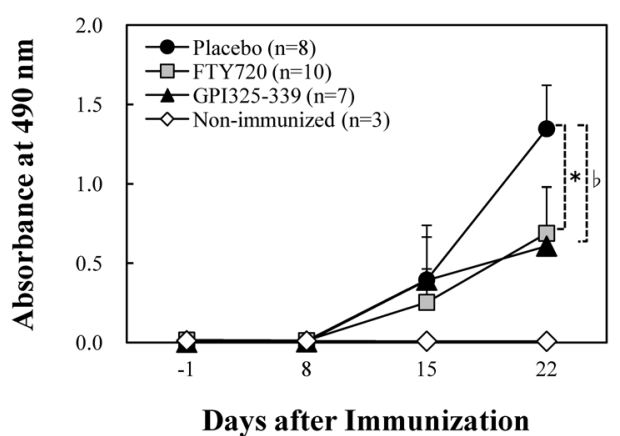

(E) $\quad$ IgG3

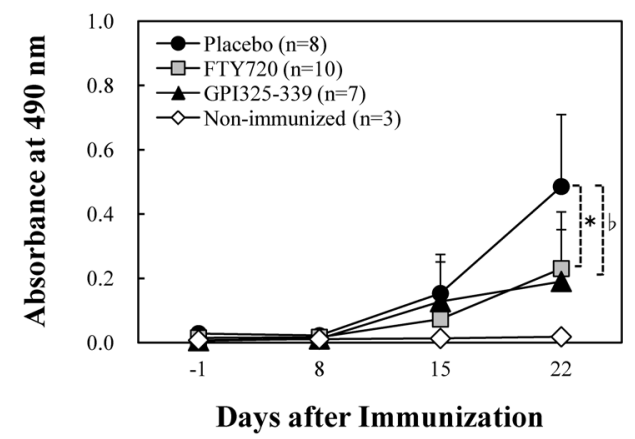

(B)

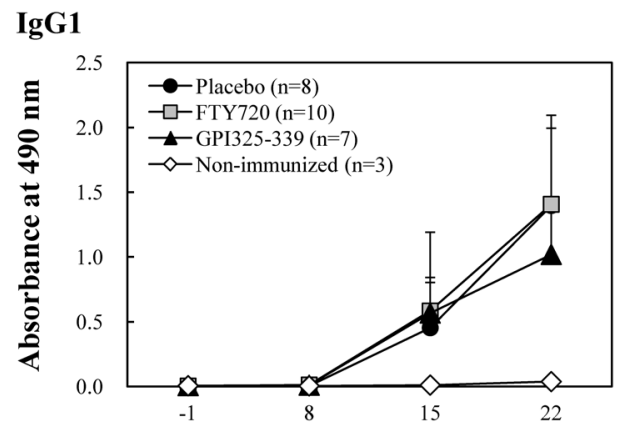

Days after Immunization

(D)

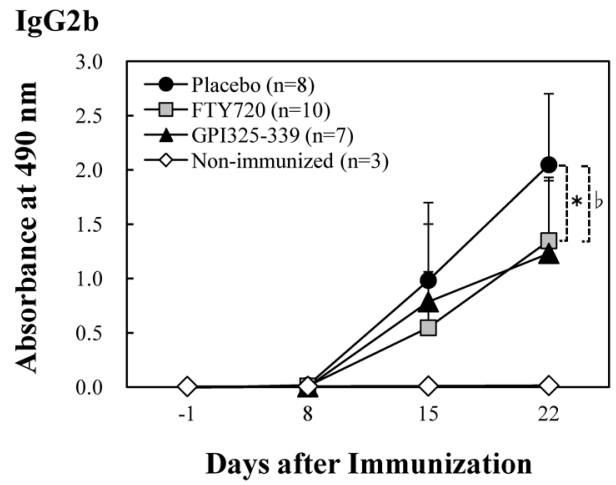

Fig. 4. Effect of FTY720 and GPI $_{325-339}$ on Production of Anti-GPI ${ }_{325-339}$ IgG Antibody Subclasses

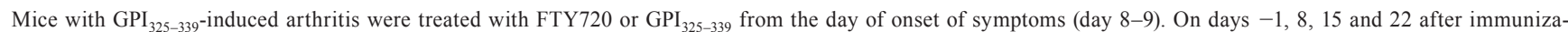

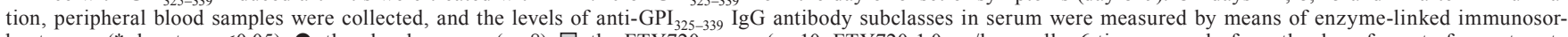
bent assay (* denotes $p<0.05)$, 0 : the placebo group $(n=8), \square$ : the FTY720 group $(n=10$, FTY720 $1.0 \mathrm{mg} / \mathrm{kg}$, orally, 6 times a week, from the day of onset of symptom to day 22), $\boldsymbol{\Delta}$ : the $\mathrm{GPI}_{325-339}$ group ( $n=7, \mathrm{GPI}_{325-339} 10 \mu \mathrm{g} / \mathrm{mouse}$, i.v. once daily, from the day of onset of symptom to day 5 ) and $\diamond:$ the non-immunized group $(n=3)$. The significance of differences in antibody level was examined (* (the FTY720 group $v s$. the placebo group), $b$ (the GPI ${ }_{325-339}$ group $v s$. the placebo group) denotes $p<0.05$ ).

Prophylactic and Therapeutic Effect of Pathogenic Autoantigen on GPI $_{325-339}$-Induced Arthritis It has already been demonstrated that i.v. administration of pathogenic autoantigen ameliorates symptoms by inducing tolerance in another animal model of RA. ${ }^{35}$ ) Thus, we first examined whether treatment with the pathogenic autoantigen $\mathrm{GPI}_{325-339}$ would suppress the development of GPI $_{325-339}$-induced arthritis-associated symptoms by inducing immune tolerance. Prophylactic administration of GPI $_{325-339}$ significantly suppressed the severity of symptoms (Figs. 1A,B). However, therapeutic administration of $\mathrm{GPI}_{325-339}$ showed only a partial effect (Figs. 3A, B). These results indicated that the tolerance is easily induced in naive animals, but primed animals are more resistant to the suppressive effect of pathogenic autoantigen administration.

Combination Treatment with FTY720 Plus GPI ${ }_{325-339}$ Ameliorates Symptoms of GPI $_{325-339}$-Induced Arthri- tis We previously reported that combination treatment with FTY720 plus pathogenic autoantigen could efficiently induce complete remission in experimental autoimmune encephalomyelitis (EAE), which is an animal model for multiple sclerosis. ${ }^{8)}$ Thus, we considered that combination treatment with FTY720 plus GPI $_{325-339}$ might ameliorate the severity of the symptoms of $\mathrm{GPI}_{325-339}$-induced arthritis. Indeed, the combination treatment for $5 \mathrm{~d}$ from the day of onset markedly reduced the severity of symptoms in all animals $(n=8)$ (Fig. 5A). The combination treatment was more effective than administration of FTY720 alone or GPI $_{325-339}$ alone (Fig. 5A). Synovial hyperplasia and inflammatory cell infiltration were also markedly suppressed in the combination group (Fig. 5B). Next, we examined whether or not aggravation of symptoms appeared after discontinuation of treatment. No clinical deterioration was observed in any of the animals $(n=4)$ up to 4 
(A)

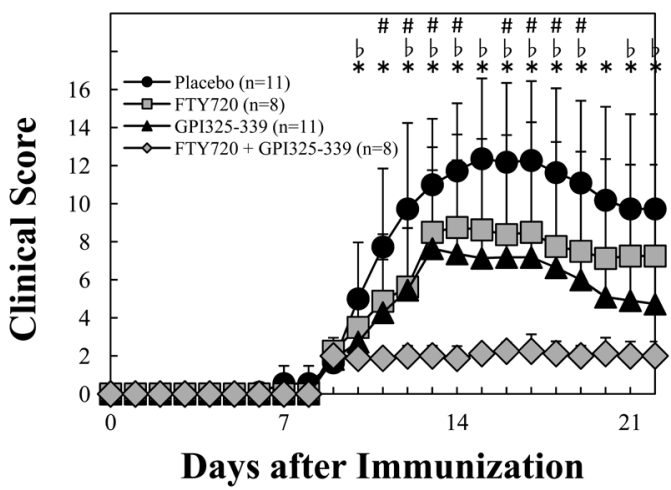

(B)

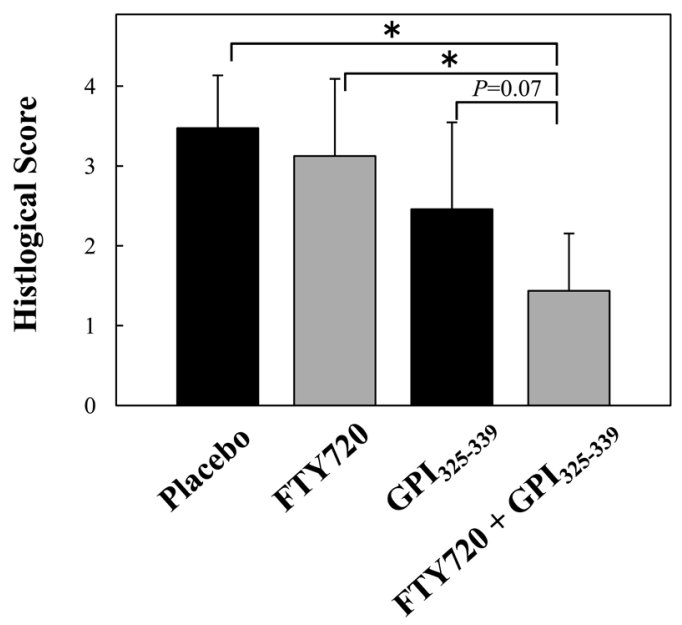

Fig. 5. Therapeutic Effect of Combination Treatment with FTY720 Plus $\mathrm{GPI}_{325-339}$ on $\mathrm{GPI}_{325-339}$-Induced Arthritis

Mice with $\mathrm{GPI}_{325-339^{-}}$-induced arthritis were treated from the day of onset of symptom (day 9 after immunization) to day 13 with GPI $_{325-339}$ alone, FTY720 alone or the combination of GPI $_{325-339}$ with FTY720. (A) Clinical symptoms of arthritis were evaluated from the day of immunization to day 22, 0 : the placebo group $(n=11), \square$ : the FTY720 group ( $n=8$, FTY720 $1.0 \mathrm{mg} / \mathrm{kg}$, orally, once daily), $\mathbf{\Delta}$ : the $\operatorname{GPI}_{325-339}$ group $\left(n=11, \mathrm{GPI}_{325-339} 10 \mu \mathrm{g} / \mathrm{mouse}\right.$, i.v. once daily) and $\diamond$ : the combination group ( $n=8$, FTY720 $1.0 \mathrm{mg} / \mathrm{kg}$, orally, once daily and $\mathrm{GPI}_{325-339} 10 \mu \mathrm{g} / \mathrm{mouse}$ i.v. once daily). The significance of differences in clinical scores was examine (* (the placebo group $v s$. the combination group), b (the FTY720 group vs. the combination group) and \# (the $\mathrm{GPI}_{325-339}$ group vs. the combination group) denotes $p<0.05$ ). (B) Mice with $\mathrm{GPI}_{325-339}$-induced arthritis were treated, as in (A). Histological score is indicated as the mean+S.D. of all mice in each group at day 22 (* denotes $p<0.05$ ).

weeks after discontinuation of treatment (data not shown). It has been reported that a booster immunization of recombinant GPI after resolution of arthritis induced a relapse in recombinant GPI-induced arthritis. ${ }^{39)}$ Mice attained remission with the combination treatment were injected as a booster with $\operatorname{GPI}_{325-339}(10 \mu \mathrm{g})$ with Freund's incomplete adjuvant at $12 \mathrm{~d}$ after discontinuation of treatment (booster immunization), and clinical symptoms were evaluated. No clinical deterioration was observed until $49 \mathrm{~d}$ after the booster immunization in all animals $(n=3)$ in the combination group (data not shown).

\section{DISCUSSION}

The novel immunomodulator fingolimod (FTY720) exerts its immunosuppressive effect via a different mechanism from those of established immunosuppressants, such as tacrolimus hydrate, and cyclosporine. FTY720 suppresses immune response by sequestering circulating mature lymphocytes from blood and peripheral tissues to the secondary lymphoid tissues and thymus. At therapeutic doses, FTY720 does not affect T or B cell responses in vitro or in vivo., ${ }^{7,10}$

RA is characterized by persistent synovitis, systemic inflammation, and autoantibodies. ${ }^{2)}$ A key feature of the inflammatory response is overexpression and overproduction of TNF, arising from interactions between $\mathrm{T}$ and B cells. ${ }^{2,40)}$ In addition, a pathological study showed that most of the lymphocytes infiltrating into the synovium in $\mathrm{RA}$ are $\mathrm{CD} 4^{+}$ (helper) T cells. ${ }^{41)}$ Thus, we hypothesized that FTY720 might be effective for treatment of rheumatoid arthritis by inducing immune suppression via sequestration of circulating mature lymphocytes from blood and joints. Our present results con-

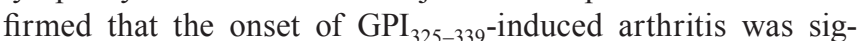
nificantly inhibited by prophylactic administration of FTY720. Therapeutic administration of FTY720 also suppressed the progression of symptoms of $\mathrm{GPI}_{325-339}$-induced arthritis, as well as synovial hyperplasia and lymphocyte infiltration.

It has been reported that $\mathrm{F} \gamma \mathrm{R} \gamma$-chain-deficient mice were protected from GPI-induced arthritis, whereas FcyRIIBdeficient mice developed exaggerated arthritis. ${ }^{19)}$ Also, Tanaka-Watanabe et al. reported that complement activation by immune complex was observed in joints of mice with GPI-induced arthritis, and they suggested that local immune complex (GPI-anti-GPI antibodies) activation in the joints also plays an important role in GPI-induced arthritis. ${ }^{42)}$ Here, we demonstrated that administration of FTY720 suppressed the production of the complement-fixing IgG subclasses (IgG2a, $\mathrm{IgG} 2 \mathrm{~b}$ and $\mathrm{IgG} 3$ ) in $\mathrm{GPI}_{325-339}$-induced arthritis and also confirmed that the complement-fixing IgG subclasses titer was correlated with clinical score (data not shown). Thus, FTY720 might suppress the severity of symptoms by preventing the synthesis of the complement-fixing IgG subclasses, although further study will be needed to establish in detail the mechanism(s) through which changes in autoantibody titer are associated with suppression of the severity of symptoms. However, FTY720 showed only a partial effect, and was less effective than other biological agents. In recipients of FTY720, reductions in circulating $\mathrm{T}$ lymphocytes are predominantly seen in the lymphoid homing receptor-expressing naïve $\mathrm{T}$ cells and central memory $\mathrm{T}$ cells. In contrast, effector memory $\mathrm{T}$ cells typically lack expression of CCR7, and thus do not recirculate regularly through lymph nodes. ${ }^{43)}$ Also, examination of blood $\mathrm{CD}^{+} \mathrm{T}$ cells from recipients of FTY720 indicates that the effector memory $\mathrm{T}$ cells that are still present in the circulation remain functionally responsive. ${ }^{43}$ This may be the reason why immune suppression was easily induced in nonimmune mice, but primed animals were resistant to the suppressive effect.

It has already been demonstrated that i.v. administration of pathogenic autoantigen ameliorates the severity of RA in another animal model by inducing tolerance. ${ }^{35)}$ As described in the Results, we demonstrated that prophylactic administration of $\mathrm{GPI}_{325-339}$ significantly suppressed the severity of symptoms. However, therapeutic administration was less effective. This result indicated that tolerance was easily induced in naïve mice, but primed mice were relatively resistant to the suppressive effect of pathogenic autoantigen.

As described in the Introduction, Kearney reported that administration of pathogenic autoantigen induces immune tolerance in the parracortical regions of all lymph nodes. ${ }^{36)}$ Thus, we considered that immune tolerance might be efficiently 
induced if sequestration of autoantigen-specific lymphocytes to secondary lymphoid tissues was induced by FTY720. In the present study, we investigated the effect of combination treatment with FTY720 plus GPI $_{325-339}$. Administration of GPI $_{325-339}$ alone or FTY720 alone was relatively ineffective, but combination treatment with FTY720 plus GPI $_{325-339}$ from the onset of symptoms strongly suppressed the severity of arthritis. Also, no clinical deterioration was observed on booster immunized-mice in combination group. To understand the mechanism(s) of this combination treatment, the anti-GPI ${ }_{325-339}$ antibody level was measured. However, the antibody titer was not correlated with the clinical score (data not shown). Thus, the mechanism(s) underlying the combination treatment was not related to only suppression of the antibody production. We considered that the combination treatment might influence not only B-cell function but also T-cell function.

We previously reported that relapse of EAE, which is an animal model for multiple sclerosis, occurred within one week after discontinuation of FTY720, with an increase in the number of lymphocytes infiltrating the spinal cord and demyelination. ${ }^{8}$ ) The timing of relapse was around the same time that lymphocyte recirculation commenced after the discontinuation. Interestingly, the relapse following discontinuation of treatment was completely suppressed by the combination treatment with FTY720 plus pathogenic autoantigen. ${ }^{8)}$ The combination treatment might have induced anergy of autoantigen-specific $\mathrm{T}$ cells responsible for the relapse on EAE. In this study, the similar results were obtained by using GPI $_{325-339}$-induced arthritis model, and revealed generality of the combination treatment. Thus, we consider that the combination treatment might efficiently induce immune tolerance by sequestering circulating autoantigen-specific lymphocytes in secondary lymphoid tissues and inducing cell tolerance. Further studies will be needed to establish in detail the mechanism(s) through which immune tolerance is induced by the combination treatment with FTY720 plus autoantigen. Possible mechanisms include induction of immunological unresponsiveness, modulation of regulatory $\mathrm{T}$ cells and induction of apoptosis of autoantigen-specific T cells.

In conclusion, our results suggest that combination treatment with FTY720 plus pathogenic autoantigen may become a breakthrough remission-induction therapy for autoimmune diseases including RA. Further investigation seems warranted.

Acknowledgments This work was supported in part by a Grant-in-Aid for Young Scientists (B) (24790483 and 24791093) from the Japan Society for the Promotion of Science and by Watanabe Memorial Foundation for The Advancement of New Technology.

\section{REFERENCES}

1) Brand DD, Latham KA, Rosloniec EF. Collagen-induced arthritis. Nat. Protoc., 2, 1269-1275 (2007).

2) Scott DL, Wolfe F, Huizinga TW. Rheumatoid arthritis. Lancet, 376, 1094-1108 (2010).

3) Takeuchi T. Revolutionary change in rheumatoid arthritis management with biological therapy. Keio J. Med., 60, 75-81 (2011).

4) Fujita $T$, Inoue $K$, Yamamoto $S$, Ikumoto $T$, Sasaki S, Toyama R, Chiba K, Hoshino Y, Okumoto T. Fungal metabolites. Part 11. A potent immunosuppressive activity found in Isaria sinclairii me- tabolite. J. Antibiot., 47, 208-215 (1994).

5) Kiuchi M, Adachi K, Kohara T, Minoguchi M, Hanano T, Aoki Y, Mishina T, Arita M, Nakao N, Ohtsuki M, Hoshino Y, Teshima K, Chiba K, Sasaki S, Fujita T. Synthesis and immunosuppressive activity of 2-substituted 2-aminopropane-1,3-diols and 2-aminoethanols. J. Med. Chem., 43, 2946-2961 (2000).

6) Matsumoto N, Hirose R, Sasaki S, Fujita T. Synthesis of the key intermediate, diethyl 2-acetylamino-2-(2-(4-octanoylphenyl)ethyl)propane-1,3-dioate, of the immunomodulatory agent FTY720 (fingolimod). Chem. Pharm. Bull., 56, 595-597 (2008).

7) Brinkmann V, Pinschewer D, Chiba K, Feng L. FTY720: a novel transplantation drug that modulates lymphocyte traffic rather than activation. Trends Pharmacol. Sci., 21, 49-52 (2000).

8) Yoshida Y, Tsuji T, Fujita T, Kohno T. Relapse of experimental autoimmune encephalomyelitis after discontinuation of FTY720 (fingolimod) treatment, but not after combination of FTY720 and pathogenic autoantigen. Biol. Pharm. Bull., 34, 933-936 (2011).

9) Kohno T, Tsuji T, Hirayama K, Iwatsuki R, Hirose M, Watabe K, Yoshikawa H, Kohno T, Matsumoto A, Fujita T, Hayashi M. A novel immunomodulator, FTY720, prevents development of experimental autoimmune myasthenia gravis in C57BL/6 mice. Biol. Pharm. Bull., 28, 736-739 (2005).

10) Kohno T, Tsuji T, Hirayama K, Watabe K, Matsumoto A, Kohno T, Fujita T. A novel immunomodulator, FTY720, prevents spontaneous dermatitis in NC/Nga mice. Biol. Pharm. Bull., 27, 1392-1396 (2004).

11) Tsuji T, Yoshida Y, Iwatsuki R, Inoue M, Fujita T, Kohno T. Therapeutic approach to steroid-resistant dermatitis using novel immunomodulator FTY720 (fingolimod) in combination with betamethasone ointment in NC/Nga mice. Biol. Pharm. Bull., 35, 1314-1319 (2012).

12) Tsuji $T$, Inoue M, Yoshida $Y$, Fujita $T$, Kaino Y, Kohno T. Therapeutic approach for type 1 diabetes mellitus using the novel immunomodulator FTY720 (fingolimod) in combination with once-daily injection of insulin glargine in non-obese diabetic mice. J. Diabetes Invest., 3, 132-137 (2012).

13) Tsuji T, Yoshida Y, Fujita T, Kohno T. Oral therapy for type 1 diabetes mellitus using a novel immunomodulator, FTY720 (fingolimod), in combination with sitagliptin, a dipeptidyl peptidase-4 inhibitor, examined in non-obese diabetic mice. J. Diabetes Invest., 3, 441-448 (2012).

14) Brinkmann V, Davis MD, Heise CE, Albert R, Cottens S, Hof R, Bruns C, Prieschl E, Baumruker T, Hiestand P, Foster CA, Zollinger M, Lynch KR. The immune modulator FTY720 targets sphingosine 1-phosphate receptors. J. Biol. Chem., 277, 21453-21457 (2002).

15) Matloubian M, Lo CG, Cinamon G, Lesneski MJ, Xu Y, Brinkmann V, Allende ML, Proia RL, Cyster JG. Lymphocyte egress from thymus and peripheral lymphoid organs is dependent on S1P receptor 1. Nature, 427, 355-360 (2004).

16) Gräler MH, Goetzl EJ. The immunosuppressant FTY720 down-regulates sphingosine 1-phosphate G-protein-coupled receptors. FASEB J., 18, 551-553 (2004).

17) Chiba K, Yanagawa Y, Masubuchi Y, Kataoka H, Kawaguchi T, Ohtsuki M, Hoshino Y. FTY720, a novel immunosuppressant, induces sequestration of circulating mature lymphocytes by acceleration of lymphocyte homing in rats. I. FTY720 selectively decreases the number of circulating mature lymphocytes by acceleration of lymphocyte homing. J. Immunol., 160, 5037-5044 (1998).

18) Yanagawa $Y$, Sugahara K, Kataoka H, Kawaguchi T, Masubuchi $Y$, Chiba K. FTY720, a novel immunosuppressant, induces sequestration of circulating mature lymphocytes by acceleration of lymphocyte homing in rats. II. FTY720 prolongs skin allograft survival by decreasing $\mathrm{T}$ cell infiltration into grafts but not cytokine production in vivo. J. Immunol., 160, 5493-5499 (1998).

19) Schubert D, Maier B, Morawietz L, Krenn V, Kamradt T. Immunization with glucose-6-phosphate isomerase induces $\mathrm{T}$ cell- 
dependent peripheral polyarthritis in genetically unaltered mice. $J$. Immunol., 172, 4503-4509 (2004).

20) Iwanami $\mathrm{K}$, Matsumoto I, Tanaka-Watanabe $\mathrm{Y}$, Inoue $\mathrm{A}$, Mihara M, Ohsugi Y, Mamura M, Goto D, Ito S, Tsutsumi A, Kishimoto T, Sumida T. Crucial role of the interleukin-6/interleukin-17 cytokine axis in the induction of arthritis by glucose-6-phosphate isomerase. Arthritis Rheum., 58, 754-763 (2008).

21) Matsumoto I, Zhang $H$, Yasukochi $T$, Iwanami $K$, Tanaka $Y$, Inoue A, Goto D, Ito S, Tsutsumi A, Sumida T. Therapeutic effects of antibodies to tumor necrosis factor-alpha, interleukin-6 and cytotoxic T-lymphocyte antigen 4 immunoglobulin in mice with glucose-6-phosphate isomerase induced arthritis. Arthritis Res. Ther., 10, R66 (2008).

22) Stuart JM, Dixon FJ. Serum transfer of collagen-induced arthritis in mice. J. Exp. Med., 158, 378-392 (1983).

23) Taurog JD, Kerwar SS, McReynolds RA, Sandberg GP, Leary SL, Mahowald ML. Synergy between adjuvant arthritis and collageninduced arthritis in rats. J. Exp. Med., 162, 962-978 (1985).

24) Tada Y, Ho A, Koh DR, Mak TW. Collagen-induced arthritis in CD4- or CD8-deficient mice: CD8 $+\mathrm{T}$ cells play a role in initiation and regulate recovery phase of collagen-induced arthritis. J. Immunol., 156, 4520-4526 (1996).

25) Kamradt T, Schubert D. The role and clinical implications of G6PI in experimental models of rheumatoid arthritis. Arthritis Res. Ther., 7, 20-28 (2005).

26) Joosten LA, Helsen MM, Saxne T, van De Loo FA, Heinegard D, van Den Berg WB. IL-1 alpha beta blockade prevents cartilage and bone destruction in murine type II collagen-induced arthritis, whereas TNF-alpha blockade only ameliorates joint inflammation. J. Immunol., 163, 5049-5055 (1999).

27) Joosten LA, Helsen MM, van de Loo FA, van den Berg WB. Anticytokine treatment of established type II collagen-induced arthritis in DBA/1 mice. A comparative study using anti-TNF alpha, antiIL-1 alpha/beta, and IL-1Ra. Arthritis Rheum., 39, 797-809 (1996).

28) Williams RO, Marinova-Mutafchieva L, Feldmann M, Maini RN. Evaluation of TNF-alpha and IL-1 blockade in collagen-induced arthritis and comparison with combined anti-TNF-alpha/anti-CD4 therapy. J. Immunol., 165, 7240-7245 (2000).

29) Butler DM, Malfait AM, Maini RN, Brennan FM, Feldmann M. Anti-IL-12 and anti-TNF antibodies synergistically suppress the progression of murine collagen-induced arthritis. Eur. J. Immunol., 29, 2205-2212 (1999).

30) Frey O, Bruns L, Morawietz L, Dunussi-Joannopoulos K, Kamradt T. B cell depletion reduces the number of autoreactive $T$ helper cells and prevents glucose-6-phosphate isomerase-induced arthritis. PLOS ONE, 6, e24718 (2011).
31) Takagi N, Mihara M, Moriya Y, Nishimoto N, Yoshizaki K, Kishimoto T, Takeda Y, Ohsugi Y. Blockage of interleukin-6 receptor ameliorates joint disease in murine collagen-induced arthritis. $\mathrm{Ar}$ thritis Rheum., 41, 2117-2121 (1998).

32) Williams RO, Whyte A. Anti-CD4 monoclonal antibodies suppress murine collagen-induced arthritis only at the time of primary immunisation. Cell. Immunol., 170, 291-295 (1996).

33) Ranges GE, Sriram S, Cooper SM. Prevention of type II collageninduced arthritis by in vivo treatment with anti-L3T4. J. Exp. Med., 162, 1105-1110 (1985).

34) Iwanami $\mathrm{K}$, Matsumoto $\mathrm{I}$, Tanaka $\mathrm{Y}$, Inoue $\mathrm{A}$, Goto $\mathrm{D}$, Ito $\mathrm{S}$, Tsutsumi A, Sumida T. Arthritogenic T cell epitope in glucose6-phosphate isomerase-induced arthritis. Arthritis Res. Ther., 10, R130 (2008).

35) Gumanovskaya ML, Myers LK, Rosloniec EF, Stuart JM, Kang $\mathrm{AH}$. Intravenous tolerization with type II collagen induces interleukin-4- and interleukin-10-producing CD4+ T cells. Immunology, 97, 466-473 (1999)

36) Kearney ER, Pape KA, Loh DY, Jenkins MK. Visualization of peptide-specific $\mathrm{T}$ cell immunity and peripheral tolerance induction in vivo. Immunity, 1, 327-339 (1994).

37) Tsunemi S, Iwasaki T, Kitano S, Imado T, Miyazawa K, Sano H. Effects of the novel immunosuppressant FTY720 in a murine rheumatoid arthritis model. Clin. Immunol., 136, 197-204 (2010).

38) Seeuws S, Jacques P, Van Praet J, Drennan M, Coudenys J, Decruy T, Deschepper E, Lepescheux L, Pujuguet P, Oste L, Vandeghinste $\mathrm{N}$, Brys R, Verbruggen G, Elewaut D. A multiparameter approach to monitor disease activity in collagen-induced arthritis. Arthritis Res. Ther., 12, R160 (2010).

39) Bockermann R, Schubert D, Kamradt T, Holmdahl R. Induction of a B-cell-dependent chronic arthritis with glucose-6-phosphate isomerase. Arthritis Res. Ther., 7, R1316-R1324 (2005).

40) Feldmann M, Brennan FM, Maini RN. Rheumatoid arthritis. Cell, 85, 307-310 (1996)

41) Struyk L, Hawes GE, Chatila MK, Breedveld FC, Kurnick JT, van den Elsen PJ. T cell receptors in rheumatoid arthritis. Arthritis Rheum., 38, 577-589 (1995).

42) Tanaka-Watanabe Y, Matsumoto I, Iwanami K, Inoue A, Goto D, Ito S, Tsutsumi A, Sumida T. B cells play a crucial role as antigenpresenting cells and collaborate with inflammatory cytokines in glucose-6-phosphate isomerase-induced arthritis. Clin. Exp. Iтmunol., 155, 285-294 (2009).

43) Mehling M, Johnson TA, Antel J, Kappos L, Bar-Or A. Clinical immunology of the sphingosine 1-phosphate receptor modulator fingolimod (FTY720) in multiple sclerosis. Neurology, 76 (Suppl. 3), S20-S27 (2011). 